\title{
EXPERIMENTAL DATA ON HIGH POWER EXPLOSIVE OPENING AND CLOSING SWITCHES AT CEM-UT
}

\author{
By: \\ R.L. Sledge \\ J. H. Hahne
}

Proceedings, Seventh IEEE Pulsed Power Conference, Monterey, California, June 11-14, 1989, pp. 151-155

PN - 153

Center for Electromechanics

The University of Texas at Austin

PRC, Mail Code R7000

Austin, TX 78712

(512) 471-4496 
EXPERIMENTAL DATA ON HIGH POWER EXPLOSIVE OPENING AND CLOSING SWITCHES AT CEM-UT

\author{
R. L. Sledge and J. H. Hahne
}

Center for Electromechanics

The University of Texas at Austin

Balcones Research Center

Building 133

Austin, TX 78758-4497

The need for high power switching in pulse power research has lead to the development of fast acting opening and closing switches with current capacity of more than $1 \mathrm{MA}$. Presented is the performance data of two switches developed for railgun experiments at the Center for Electromechanics at The University of Texas at Austin (CEM-UT). The first is a compact closing switch, explosively actuated, used as an isolation device for staging parallel inductors charged by homopolar generators (HPGs) and as a crowbar to shunt excess energy from railguns during projectile exit. The second is an explosive opening switch which provides a low resistance path during inductor charging before quickly opening to transfer energy to the railgun.

\section{CLOSING SWITCH DESIGN}

The original design, as reported by Peterson 1 has evolved into several new closing switches that are used in a variety of ways at CEM-UT. The newest design utilizes a ring of $3.2 \mathrm{~g} / \mathrm{m}$ (15 grains/foot $(g r / f t))$ detonating cord to propel a copper throwring (10.31 inner diameter $\times 12.40$ outer diameter $\times 0.64 \mathrm{~cm}$ thick) into a tapered coaxial gap between two steel catch pieces. Prior to detonation, the detonating cord and the throwring are held in a polyethylene cartridge. The steel catch pieces are reusable for many shots with minimal cleaning, however the cartridge and the throwring are expendable. The initiation of the detonating cord is done at two diametrically opposite points and the explosion propagates in both directions from each point. The time required for the switch to detonate is the time required for the cord to burn one-quarter of the way around the ring, about $10 \mu \mathrm{s}$. The copper throwring has shallow radiused serations or "scallops" machined on the inner and outer circumferences to provide multiple high pressure contacts as the ring is forced into the tapered gap. The throw rings, CNC-machined from $6.35 \mathrm{~mm}(0.25 \mathrm{in.})$ thick $\mathrm{c} 11000$ electrolytic tough pitch copper sheet, are annealed after machining for optimal seating in the taper. This versatile design has been utilized for several important switching requirements.

The switch was originally designed to shunt, or crowbar, excess current from the breech of HPG and capacitor bank powered railguns. Proper crowbarring of a railgun breech just prior to projectile exit of the gun is important to minimize damage to the muzzle, prevent projectile tip-off from a large muzzle blast, and eliminate excessive electromagnetic noise from the muzzle arc. Due to the reliable fast actuation of the switch, it has effectively crowbarred plasma armature hypervelocity railgun experiments which require precise timing (fig. 1). The high action capacity of the switch has made it most effective in crowbarring large solid armature tactical railgun experiments which have high exit currents, up to $1.5 \mathrm{MA}$.

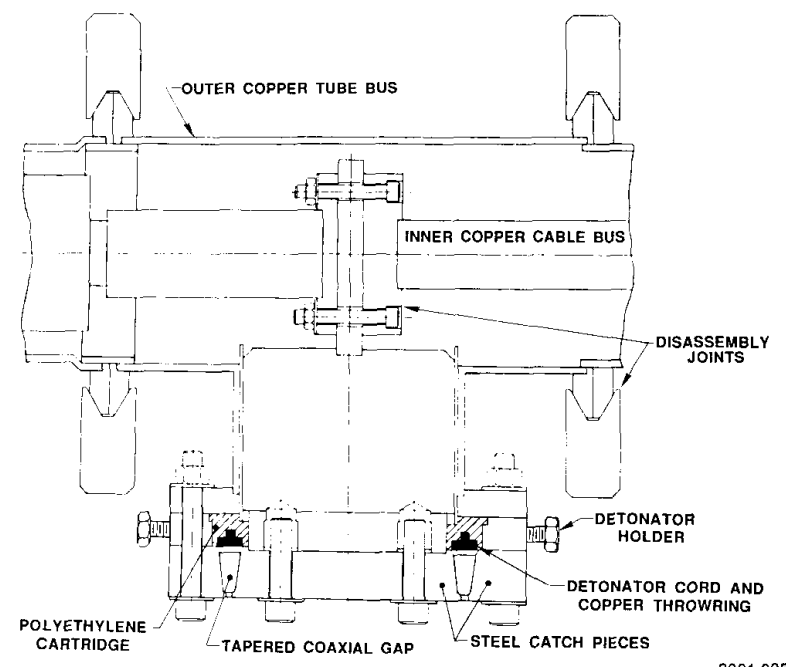

3001.0055

Figure 1. Coaxial version of closing switch which crowbars hypervelocity railgun experiments

Because of the switch's low resistance, it has found an important role in compulsator powered railgun experiments in which current is transferred with precise timing to a solid armature railgun injector. since circuit voltage is relatively low, the explosive switch has replaced an ignitron, which is more resistive by two orders of magnitude. The switch provides repeatable timing, thereby preventing damage to the injector and railgun. [2]

The staging of parallel HPG-charged inductors allows for shaping current waveforms to the requirements of the specific load (fig. 2). Ignitrons were found to have a Coulomb rating which is not adequate for passing large currents for the extended time periods of these experiments. Two switches in parallel have successfully replaced two ignitrons as the device for isolating and staging (fig. 3). In this role the isolation switch must be able to hold off voltages up to $15 \mathrm{kV}$ generated by parallel opening switches when commutating current. When the switch is closed, it must carry current for the duration of the gun shot as well as the decay time after the breech crowbars close. The isolation/staging switch design has successfully demonstrated its ability to hold off high voltages and pass large currents for long time periods. 


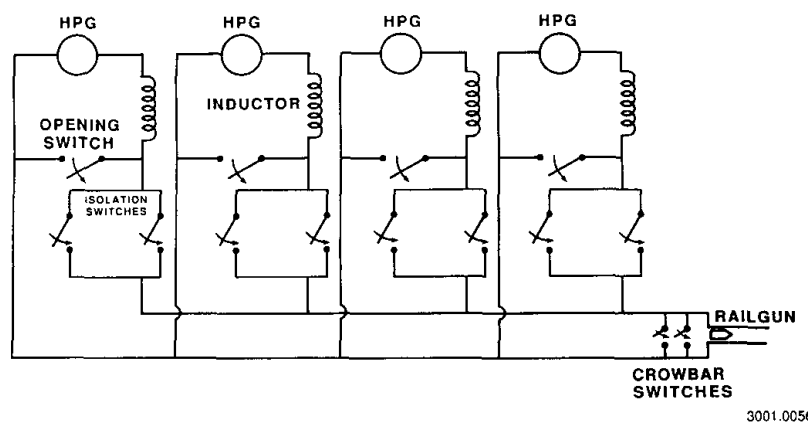

Figure 2. Opening and closing switches required in staging multiple HPG-charged inductors for a high power railgun experiment

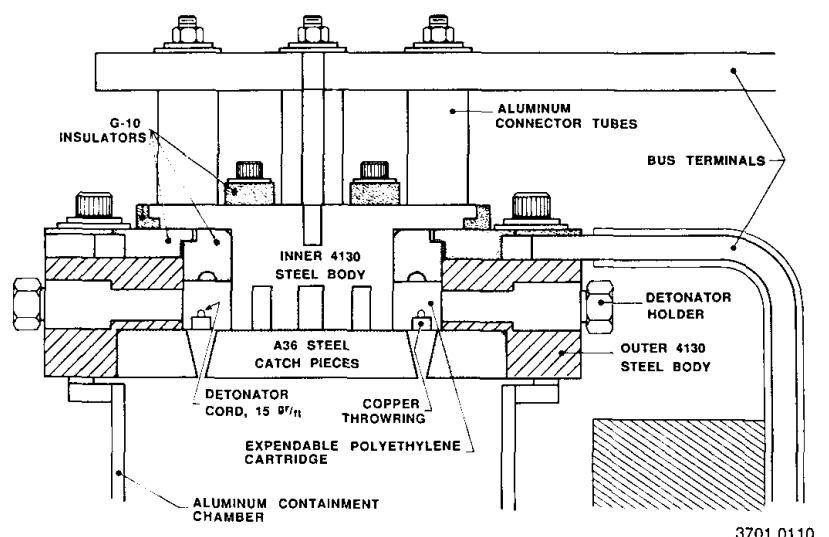

Figure 3. Parallel busbar version of closing switch used in isolating and staging multiple HPG-charged inductors

\section{CLOSING SWITCH PERFORMANCE}

Experimental characteristics and peak performance are as shown:

- Time between detonator signal and current beginning in switch (jitter $= \pm 10 \mu \mathrm{s}) \ldots . .80 \mu \mathrm{s}$

- Typical di/dt...................5,000 A/us

- Switch resistance including switch body... $10 \mu \Omega$

- Switch inductance including switch body... $100 \mathrm{nH}$

- Peak voltage holdoff.................. $14 \mathrm{kV}$

- Peak switch current to date.............1.14 MA

- $I^{2} t$ rating (peak $\int i^{2} d t$ to date) $-1.70 \times 10^{10} \mathrm{~A}^{2}: \mathrm{s}$

The $I^{2} t$, or action, rating is an indication of how long the switch will carry a high current without thermally damaging the catch pieces, which, at the contact interface, have a lower action rating than the throwring because the catch pieces are made of steel. Based on the total contact area around the scallops and the specific action constant of melt beginning for iron ${ }^{3}$, the theoretical $I^{2} t$ rating was calculated:

$$
\begin{aligned}
I^{2} t & =\left(1,216 \mathrm{~mm}^{2}\right)^{2}\left(12,806 \mathrm{~A}^{2} \cdot \mathrm{s} / \mathrm{mm}^{4}\right) \\
& =1.89 \times 10^{10} \mathrm{~A}^{2} \cdot \mathrm{s}
\end{aligned}
$$

This compares to the empirical value of $1.70 \times 10^{10} \mathrm{~A}^{2}$ - s. The values are within 10\%, suggesting that the throwring seats very well and utilizes the aviailable contact area.

This switch is a candidate for a fusion magnet experiment with requirements of $1.5 \mathrm{MA}$ and $11 \mathrm{x}$ $10^{10} \mathrm{~A}^{2} \cdot \mathrm{s}$. The use of copper instead of s:eel as the catch piece material should increase the $I^{2} t$ capacity of the switch by a factor of six, although a weaker material may withstand fewer shots. Preliminary mechanical tests have beer made using copper catch pieces made of readily available copper plate with $1 / 8$ hard temper. Several tests resulted in contact surface deformation of a degree which should not impair performance. A test involving a tivo fold increase in throwring diameter is also planned.

\section{OPENING SWITCH DESIGN}

Design and testing of several explosive opening switches used at CEM-UT were reported by Peterson 1 , Rech $^{4,5}$ and Sledge 6 . Presented here are higher energy test data and a summary of mechanical improvements for the "monolithic" switch discussed in references 5 and

The parallel plate configuration of the switch, incorporated in the buswork of six, $10 \mathrm{MJ}$ HPG charged inductors, is shown in figure 4. The switch uses an a) uminum switch element, $60.96 \mathrm{~cm}$ wide, made of 2.54 $\mathrm{cm}$ thick aluminum with either four or seven rachined stress concentrations. A $10.6 \mathrm{~g} / \mathrm{m}(50 \mathrm{gr} / \mathrm{ft})$ detonating cord shears the $3.96 \mathrm{~mm}(0.156 \mathrm{in.})$ th ck section of metal above the machined gaps. Seven gaps, instead of the usual four, are employed when switching into higher impedance loads such as plasma armature railguns. Gaps are detonated from each side, using a short length of $3.2 \mathrm{~g} / \mathrm{m}(15 \mathrm{gr} / \mathrm{ft})$ detonating cord which feeds into steel detonator feedthru blocks on either side of a steel containment vessel (no: shown) around the switch. The feedthru blocks permit exploding bridgewire detonators to be instal ed just prior to the experiment, without unbolting the containment.

Mechanical improvements were required as: higher explosive arc and magnetic pressures were encountered. Shown in figure 4 is the present design of the switch. opening arcs are expanded with explosive gasses and magnetic pressure into air and into a polyethylene foam with a density of $96 \mathrm{~kg} / \mathrm{m}^{3}\left(6 \mathrm{lb} / \mathrm{ft}^{3}\right)$. A copper commutation busbar, slotted for venting of the arc blast, has polyethylene protectors to prevent arc coupling. Also featured is an $\mathrm{S}-2$ glass filament wound, epoxy impregnated, support block required to react the simultaneous blast pressure and magnetic loading on the commutation busbar. A G-10 plate is bolted to and supports the switch element from a magnetic pressure of 200 psi during inductor charging to $1.2 \mathrm{MA}$.

\section{OPENING SWITCH PERFORMANCE}

As of the last reporting, the opening suitch had opened currents up to $708 \mathrm{kA}$ and developed voltages up to $6 \mathrm{kV}$. Switching of current up to $650 \mathrm{kA}$ ir to loads of up to $1 \mu \mathrm{H}$ and $1 \mathrm{~m} \Omega$ resulted in switch efficiencies of 92 to $94 \%$. Switching into loads of higher impe- 


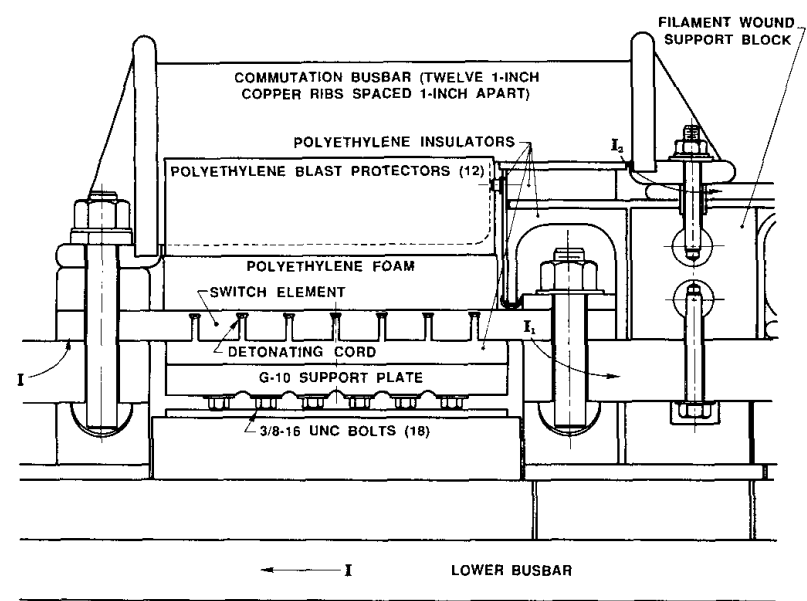

3001.0057

Figure 4. Monolithic element opening switch used in the Balcones $60 \mathrm{MJ}$ power supply

dance yielded efficiencies in the low $80^{\prime} \mathrm{s}$. A switch characterization of resistance vs. time was illustrated along with a table of performance and calculation methods for switching efficiency, load inductance, and load resistance ${ }^{6}$. Opening time was defined as the time interval in which switch current changes from 100 to $2 \%$ of initial value. This convention is preferred at CEM-UT over the standard 90 to 10\% convention because of higher accuracy. An HPG/inductor/opening switch circuit diagram with electrical parameters was presented by Gul1y 8 .

New performance data are given in table 1 . Switch efficiencies are slightly lower (85 to 90\%) for currents over $650 \mathrm{kA}$ switching into $1 \mu \mathrm{H}, 1 \mathrm{~m} \Omega$ loads, as shown in table 1 , rows 1,2 , and 4 . Plotted in figure 5 are theoretically and experimentally determined values for switch energy absorption at various currents. Experimental values were calculated as follows:

$$
E=\int v i d t
$$

where $v$ is the voltage across the switch and $i$ is the current through the switch during the opening time, using the 100 to $2 \%$ convention. Theoretical energy absorption was calculated using :

$$
E=\frac{1}{2} I^{2} \frac{L_{1} L_{2}}{L_{1}+L_{2}}
$$

where $L_{1}$ and $L_{2}$ are the inductances of the primary and secondary circuits and $I$ is the initial switch current. For the primary circuit including the $6.5 \mu \mathrm{H}$ inductor, $L_{1}=6.94 \mu \mathrm{H}$. The secondary circuit inductance of $L_{2}=0.67 \mu \mathrm{H}$ was calculated for this plot by averaging experimentally determined load inductances, varying from 0.36 to $1.15 \mu \mathrm{H}$, for each experiment plotted.

A typical time from detonator signal until the first indication of current decreasing through the

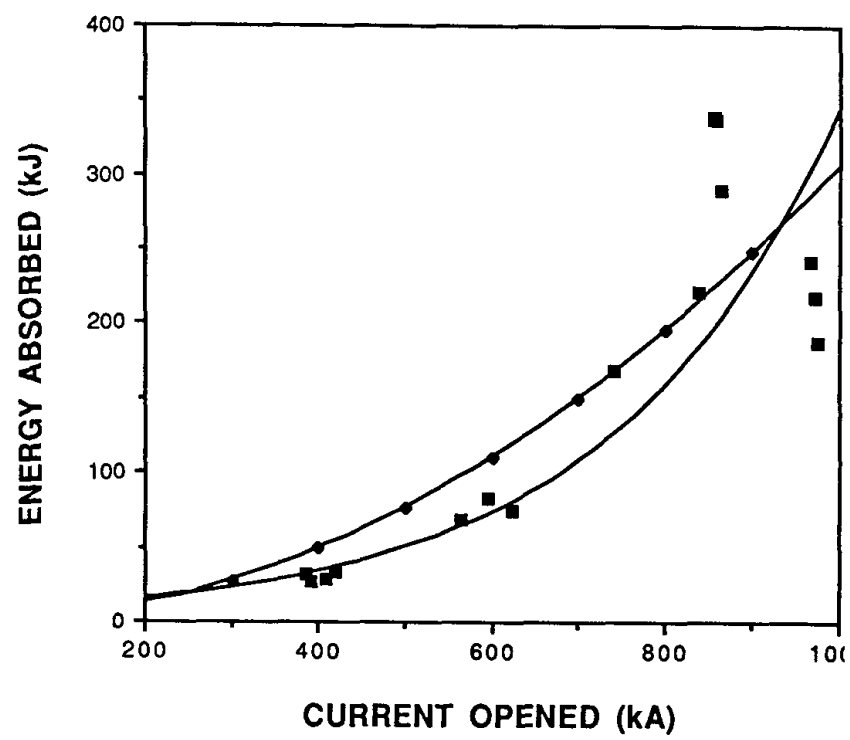

- ENERGY ABS

- CALC E L2 $=67$

Figure 5. Theoretical and experimental values of opening switch absorbed energy vs. current

switch is $103 \mu \mathrm{s}$ as shown in Table 1. Although detonating cord length is consistent from shot to shot, jitter times of \pm 28 us have been experienced. Reasons for this magnitude of jitter are presently unknown.

New peak current and voltage values are $1.22 \mathrm{MA}$ and $12 \mathrm{kV}$. In the $1.22 \mathrm{MA}$ experiment, the switch gaps were intentionally melted open by allowing excessive $\mathrm{I}^{2} \mathrm{t}$ in the switch before explosive detonation (see table 1, row 6). The switch fully opened in $6.2 \mathrm{~ms}$, before detonation. The purpose of the experiment was to test busbar clamping at peak current, and to determine an accurate specific action constant for the switch element so that it could be accurately sized for passive thermal failure in the event of detonation failure. Passive opening capability is desired to prevent HPG rotor reversal due to an underdamped ringing circuit. The switch element thickness was measured carefully before the test to get an accurate area. Specific action was calculated using area and the value of $I^{2} t$ up to the time when current began decreasing, as follows:

$$
\begin{aligned}
g=\frac{I^{2} t}{A^{2}} & =\frac{1.357 \times 10^{10} A^{2}}{\left(2,262.6 \mathrm{~mm}^{2}\right)^{2}} \\
& =29,016 \frac{A^{2} \cdot \mathrm{s}}{\mathrm{mm}^{4}}
\end{aligned}
$$

When switch current reached zero, the $I^{2} t$ was $1.43 \times 1011 \mathrm{~A}^{2}$. s corresponding to a specific action of $30,620 \mathrm{~A}^{2} \cdot \mathrm{s} / \mathrm{mm}^{4}$.

These compare to published action constants for aluminum of: 
Table 1. New performance data for the four-gap monolithic opening switch

\begin{tabular}{|c|c|c|c|c|c|c|c|c|c|c|}
\hline $\begin{array}{c}\text { Shot } \\
\text { Number }\end{array}$ & $\begin{array}{l}\text { Power } \\
\text { Supply }\end{array}$ & $\begin{array}{c}\text { Load } \\
\text { Inductance } \\
(\mu \mathrm{H})\end{array}$ & $\begin{array}{c}\text { Load } \\
\text { Resistance } \\
(\mathrm{m} \Omega) \\
\end{array}$ & $\begin{array}{l}\text { Current } \\
\text { Opened } \\
\text { (kA) }\end{array}$ & \begin{tabular}{|c|} 
Current \\
Transferred \\
(kA)
\end{tabular} & $\begin{array}{l}\text { Opening } \\
\text { Time } \\
(\mu s)\end{array}$ & \begin{tabular}{|c|}
$\begin{array}{c}\text { Time to first } \\
\text { current drop } \\
(\mu \mathrm{S})\end{array}$ \\
\end{tabular} & \begin{tabular}{|c|}
$\begin{array}{c}\text { Peak Switch } \\
\text { Voltage } \\
(\mathrm{kV})\end{array}$ \\
\end{tabular} & $\begin{array}{l}\text { EABS } \\
(\mathrm{kJ}) \\
\end{array}$ & $\begin{array}{c}\text { Siwitch } \\
\text { Efticiency } \\
(\%)\end{array}$ \\
\hline $3-M \# 13$ & $\begin{array}{l}\text { two } \\
\text { HPGs }\end{array}$ & $\begin{array}{c}0.6 \\
-\ldots\end{array}$ & $\begin{array}{c}1 \\
-.\end{array}$ & $\begin{array}{l}740 \\
729\end{array}$ & $\begin{array}{l}666 \\
653\end{array}$ & $\begin{array}{l}120 \\
105\end{array}$ & $\begin{array}{l}75 \\
75\end{array}$ & $\begin{array}{l}5.7 \\
\cdots .\end{array}$ & $\begin{array}{l}169 \\
\ldots\end{array}$ & $\begin{array}{c}90 \\
--\end{array}$ \\
\hline $10-M \quad \# 1$ & $\begin{array}{l}\text { three } \\
\text { HPGs }\end{array}$ & $\begin{array}{l}1 \\
1\end{array}$ & \begin{tabular}{c}
0.9 \\
\hdashline-9 \\
0.9
\end{tabular} & $\begin{array}{l}857 \\
837 \\
863\end{array}$ & $\begin{array}{l}737 \\
723 \\
746\end{array}$ & $\begin{array}{l}140 \\
150 \\
140\end{array}$ & $\begin{array}{c}110 \\
95 \\
90\end{array}$ & $\begin{array}{l}7.6 \\
5.8 \\
7.5\end{array}$ & $\begin{array}{l}338 \\
222 \\
290\end{array}$ & $\begin{array}{l}85 \\
90 \\
87\end{array}$ \\
\hline $10-M \quad \# 4$ & $\begin{array}{l}\text { four } \\
\text { HPGs }\end{array}$ & $\begin{array}{c}2 \\
1 \\
-\ldots \\
\cdots\end{array}$ & $\begin{array}{c}6 \\
4 \\
\cdots \\
-. \\
\end{array}$ & $\begin{array}{l}971 \\
970 \\
992 \\
971\end{array}$ & $\begin{array}{l}818 \\
846 \\
799 \\
743\end{array}$ & $\begin{array}{l}175 \\
175 \\
\cdots \\
\ldots\end{array}$ & $\begin{array}{c}95 \\
100 \\
\cdots \\
100\end{array}$ & $\begin{array}{l}7.7 \\
8.5 \\
5.1 \\
7.8\end{array}$ & $\begin{array}{c}459 \\
404 \\
\ldots \ldots \\
\ldots\end{array}$ & $\begin{array}{c}84 \\
86 \\
\cdots \\
\cdots\end{array}$ \\
\hline $10-M \quad \# 9$ & $\begin{array}{l}\text { five } \\
\text { HPGs }\end{array}$ & $\begin{array}{c}0.7 \\
\cdots \\
0.6 \\
\cdots \\
\cdots\end{array}$ & $\begin{array}{c}0.8 \\
\cdots \\
3 \\
\cdots \\
\cdots\end{array}$ & $\begin{array}{l}975 \\
973 \\
966 \\
974 \\
970\end{array}$ & $\begin{array}{l}843 \\
843 \\
822 \\
793 \\
837\end{array}$ & $\begin{array}{l}145 \\
150 \\
125 \\
--. \\
\cdots\end{array}$ & $\begin{array}{c}80 \\
85 \\
105 \\
130 \\
-\ldots\end{array}$ & $\begin{array}{l}5.8 \\
5.6 \\
6.8 \\
7.9 \\
-. .\end{array}$ & $\begin{array}{l}188 \\
218 \\
242 \\
\ldots \\
\ldots\end{array}$ & $\begin{array}{c}93 \\
92 \\
91 \\
\ldots- \\
\ldots\end{array}$ \\
\hline $10-M \quad \# 7$ & one HPG & $\cdots$ & $\cdots$ & 1110 & 1030 & 105 & 100 & 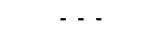 & $\ldots$ & $\ldots$ \\
\hline $\begin{array}{c}\text { Switch } \\
\text { experiment }\end{array}$ & one HPG & (no load) & $\begin{array}{c}\infty \\
\text { (no load) }\end{array}$ & 1220 & NA & 6200 & NA & 1.2 & 4460 & NA \\
\hline
\end{tabular}

- Insufficient data available

Melt beginning $g=25,238 \mathrm{~A}^{2} \cdot \mathrm{s} / \mathrm{mm}^{4}$ Melt ending $g=32,035 \mathrm{~A}^{2} \cdot \mathrm{s} / \mathrm{mm}^{4}{ }^{2}$

After this test, the specified standard switch area was changed to $2,415 \mathrm{~mm}^{2}$, corresponding to a maximum $I^{2} t$ of $1.69 \times 10^{11} \mathrm{~A}^{2}$ - s required for proposed railgun experiments. If necessary, the $I^{2} t$ capacity of the monolithic switch could be increased to $3.89 \times 10^{11} \mathrm{~A}^{2}$ - $s$ by increasing the section of metal above the gap to $6.35 \mathrm{~mm}(0.25 \mathrm{in}$.$) thick. This thickness was$ sheared successfully using $21.2 \mathrm{~g} / \mathrm{m}(100 \mathrm{gr} / \mathrm{ft}) \operatorname{cord}^{5}$.

\section{CONCLUSION}

The explosively actuated closing switch developed at CEM-UT has demonstrated its advantages. Because of repeatable rapid closing and high $I^{2} t$ capacity it has been used to replace ignitrons in several high power circuits. Due to the switch's compact coaxial design, the assembly is mechanically rigid and easily adapted to both coaxial and flat-plate bus geometries. Direct metal contacts in the switch eliminate large voltage drops inherent to arc initiated closing switches. High current flowing in the closed switch provides a large magnetic pressure that assists in maintaining adequate contact pressure between the throwring and catchpieces.

The utility of the monolithic opening switch has been demonstrated in a multitude of tests. To efficiently power a hypervelocity railgun experiment, switching must be completed quickly with respect to projectile in-bore residence time. For these experiments currents of less than $500 \mathrm{kA}$ were opened in 45 to $95 \mu \mathrm{s}$, less than $15 \%$ of residence time. The challenge of powering long $(10 \mathrm{~m})$ tactical railguns with more massive payloads has been met by opening currents of $500 \mathrm{KA}$ to $1.2 \mathrm{MA}$ in 100 to $175 \mu \mathrm{s}$ and holding off voltages for long times (10 ms).

Railguns at CEM-UT are successfully powered with compulsators and HPG's employing these fast acting explosive switches. Through the use of staged HPG inductive power supplies, the switches are instrumental in meeting specific experimental requirements by allowing a wide variety of power conditioning and pulse shaping. Both of the switches have proven high $I^{2} t$ capacity and their ability to transfer currents of over 1 MA.

\section{ACKNOWLEDGEMENT}

The funding for this work was provided by the Defense Advanced Research Projects Organization and the Strategic Defense Initiative office under the U.S. Army Armament Research, Development, and Engineering Center.

\section{REFERENCES}

1. D. R. Peterson, R. C. Zowarka, and B. M. Rech, "Switch Development at CEM-UT," 5th IEEE Pulsed Power Conference, Arlington, VA, 1985.

2. T. J. Tucker and R. P. Toth, "EBWI: A zomputer Code for the Prediction of the Behavior and Electrical Circuits Containing Exploding Wire Elements," U.S. Energy Research and Development Administration, Project No. AT (29-1)-789. Apri1, 1975, Sandia Laboratories, SAND-75-0041.

3. R. F. Thelen, "Pulse Discharge Control and Machine Protection for a Multi-Discharge Compulsator," 4 th Symposium on Electromagnetic Launch Technology, April 1988, Austin, TX. 
4. B. M. Rech and R. C. Zowarka, Jr., "Design and Construction of a Two-Stage Opening Switch," 3rd Syposium on Electromagnetic Launch Technology, April 1986, Austin, TX.

5. B. M. Rech, "High Coulomb Single Stage Opening Switches," 6th IEEE Pulsed Power Conference, June 1987, Arlington, VA.

6. R. L. Sledge, D. E. Perkins, and B. M. Rech, "High Power Switches at the Center for Electromechanics at The University of Texas at Austin," 4th Symposium on Electromagnetic Launch Technology, Aprit 1988, Austin, TX.

7. J. H. Gully, D. J. Hildenbrand, and W. F. Weldon, "Balcones Homopolar Generator Power Supply," 4th Symposium on Electromagnetic Launch Technology, April 1988, Austin, TX. 